\title{
100 MW ELECTRON GUN FOR A 34.3 GHZ MAGNICON *
}

\author{
V.P. Yakovlev, ${ }^{1}$ O.A. Nezhevenko, ${ }^{1}$ M.A. LaPointe, ${ }^{1,2}$ J.L. Hirshfield, ${ }^{1,2}$ \\ M.A. Batazova, ${ }^{3}$ and G.I. Kuznetsov ${ }^{3}$ \\ 'Omega-P, Inc., 345 Whitney Ave., Suite 100, New Haven, CT 06511, USA \\ ${ }^{2}$ Yale University, Beam Physics Lab, 272 Whitney Ave., New Haven, CT 06511 USA \\ ${ }^{3}$ Budker INP, Novosibirsk, 630090, Russia
}

\begin{abstract}
A $100 \mathrm{MW}$ advanced Pierce gun is described that was built for a $34.3 \mathrm{GHz}$ magnicon amplifier. The gun has a computed beam diameter of $\sim 0.9 \mathrm{~mm}$ when matched into a $13 \mathrm{kG}$ magnetic field. The diameter of the cathode is 50 $\mathrm{mm}$. Hence, the beam area compression ratio is $~ 3000: 1$.
\end{abstract}

\section{INTRODUCTION}

The magnicon, a RF source based on circular deflection of an electron beam, is an attractive alternative to the klystron for accelerator applications [1]. Currently, a 34.3 $\mathrm{GHz}$ magnicon [2] is under construction by Omega-P, Inc. This magnicon is expected to have a peak output power of $45 \mathrm{MW}$ in a $1.0 \mu \mathrm{sec}$ pulse with repetition rate of up to $10 \mathrm{~Hz}$. This paper describes a $500 \mathrm{kV}, 220 \mathrm{~A}$ (perveance $\sim 0.62 \times 10^{-6} \mathrm{~A}-\mathrm{V}^{-3 / 2}$ ) gun for this RF source. The gun provides a low emittance electron beam with diameter of $0.9 \mathrm{~mm}$ in the magnicon superconducting magnetic system with a field of $13 \mathrm{kG}$. The Brillouin limit diameter is about $0.7 \mathrm{~mm}$.

\section{THE GUN DESIGN}

The gun described here is a Pierce diode with extremely high beam area compression. The main gun parameters are listed in Table I. In order to obtain reasonable cathode lifetime (20,000-30,000 hrs), the dispenser cathode diameter is chosen to be $50 \mathrm{~mm}$, limiting loading to 12 $\mathrm{A} / \mathrm{cm}^{2}$ [3]. To achieve required beam diameter in the magnicon magnetic system (see Fig. 1 and Ref. 2), two stage compression is used [4], as proven for the $7 \mathrm{GHz}$ magnicon [5], and for the $11.4 \mathrm{GHz}$ magnicon [6]. Compression in this gun is only partially electrostatic (500:1), since more than this would lead to a higher electric field at the focus electrode; and would require a magnetic field of about $13 \mathrm{kG}$ at the edge of the pole piece, leading to saturation in the iron [4]. Thus, magnetic compression of about 2:1 occurs as the beam passes through the hole in the pole piece into a $\sim 5 \mathrm{kG}$ field, and a further factor of 3:1 occurs adiabatically as the magnetic field gradually rises up to $13 \mathrm{kG}$.

The gun schematic and simulated trajectories are shown in Fig. 2. The shape of electrodes was optimized to achieve the required perveance, acceptable electrostatic field gradient level and minimum geometrical aberrations.
Table I. Design parameters of the gun for the Omega-P $34.3 \mathrm{GHz}$ magnicon.

\begin{tabular}{|l|l|}
\hline beam power, $\mathrm{MW}$ & 109 \\
\hline beam voltage, $\mathrm{kV}$ & 500 \\
\hline beam current, $\mathrm{A}$ & 218 \\
\hline perveance, $\mathrm{A}-\mathrm{V}^{-3 / 2}$ & $0.62 \times 10^{-6}$ \\
\hline pulse duration, $\mu \mathrm{sec}$ & 1 \\
\hline cathode diameter, mm & 50 \\
\hline beam diameter in magnetic system, mm & 0.9 \\
\hline beam area compression ratio & $3000: 1$ \\
\hline electrostatic compression & $500: 1$ \\
\hline magnetic compression & $6: 1$ \\
\hline $\begin{array}{l}\text { maximum electric field on the focusing } \\
\text { electrode, } \mathrm{kV} / \mathrm{cm}\end{array}$ & 238 \\
\hline maximum cathode loading, A/cm ${ }^{2}$ & 12 \\
\hline transverse beam emittance, mrad-cm & $1.0 \pi$ \\
\hline $\begin{array}{l}\text { aberration contribution to the emittance, } \\
\text { mrad-cm }\end{array}$ & $0.2 \pi$ \\
\hline $\begin{array}{l}\text { beam energy density in magnetic } \\
\text { system, } \mathrm{kJ} / \mathrm{cm}^{2}\end{array}$ & 17 \\
\hline
\end{tabular}

The product of maximum surface electric field $E_{\max }$ and gap voltage $V$ which characterizes the gun electric strength [7] is $1.2 \cdot 10^{4}(\mathrm{kV})^{2} / \mathrm{mm}$. This is below the value $\sim 1.5 \cdot 10^{4}(\mathrm{kV})^{2} / \mathrm{mm}$ for high-voltage guns for X-band klystrons at SLAC operating with longer pulses $[7,8]$.

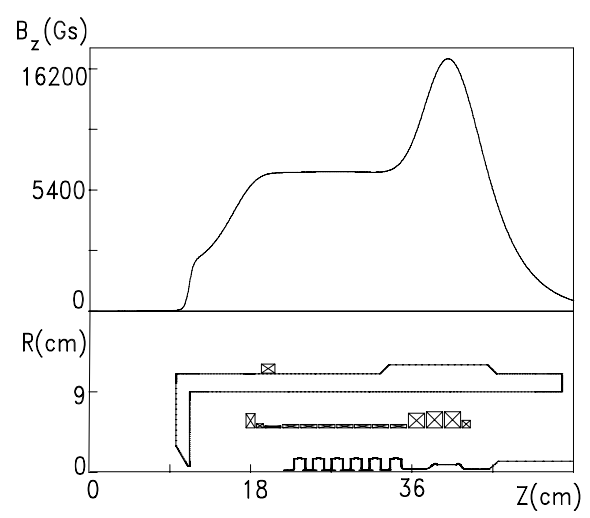

Figure 1. Magnetic system layout and magnetic field profile.

\footnotetext{
* Research supported by U.S. DoE.
} 


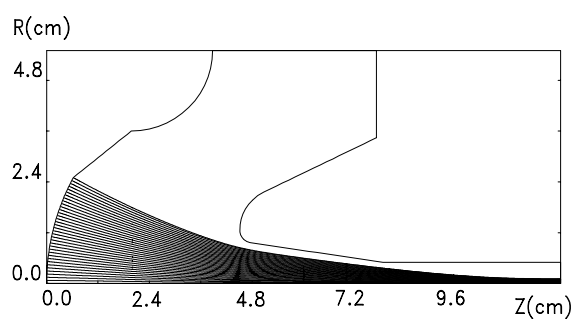

Figure 2. Gun electrode outlines and sample computed electron trajectories, as computed using SuperSAM [9].

Stray magnetic field on the cathode is cancelled using the compensation coil shown in Fig.1 on the outer side of magnetic yoke.

The fundamental limitation on the beam diameter in a magnetic system for a gun with compensated geometrical aberration is due to the beam thermal emittance [4].

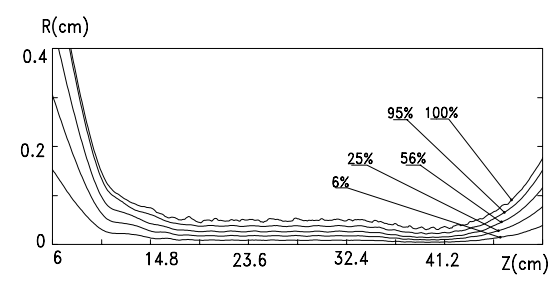

Figure 3. Computed radial limits for $6 \%, 25 \%, 56 \%$, $95 \%$, and $100 \%$ of the beam current.

In Fig. 3 are shown beam envelopes contours calculated taking into account thermal spread of the transverse velocities of the beam electrons. In the region where magnetic field is $13 \mathrm{kG}$, the beam radius is still close to Brillouin, with $100 \%$ of the current within a diameter of $0.9-\mathrm{mm}$, and $95 \%$ within $0.8-\mathrm{mm}$.

In addition to thermal spread of transverse velocities, cathode surface roughness may contribute to the effective beam temperature if the roughness scale $d$ is greater than the distance between the cathode and the potential minimum (virtual cathode). Simulations show that the roughness contribution to the effective beam temperature $\Delta T$ may be estimated by the following formula: $\Delta T\left[{ }^{\circ} \mathrm{C}\right] \approx$ $k j^{2 / 3}\left[\mathrm{~A} / \mathrm{cm}^{2}\right] d^{4 / 3}[\mu]$, where $j$ is the cathode current density, and $k$ is a factor of order unity. For dispenser cathodes, surface roughness scale $d$ is a few microns, so for a current density of $12 \mathrm{~A} / \mathrm{cm}^{2}$ the effective temperature increase caused by the cathode surface roughness is less than $50^{\circ} \mathrm{C}$.

Another cause for increase of beam emittance and halo formation is the electron emission from the cathode edge and from the cylindrical side of the cathode. To suppress this emission in the gun for the $11.4 \mathrm{GHz}$ magnicon [6] an electrically isolated focus electrode biased negative with respect to the cathode was used. However, it is technically complex to realize this arrangement. In the gun described here another method is applied, in which the cathode edge is surrounded by a molybdenum ring, cut at the Pierce angle with respect to cathode surface.
The thermal gap is $3 \mathrm{~mm}$ from the cathode edge, and its width is not greater than $0.2 \mathrm{~mm}$ when heated, and thus does not affect the beam. Numerical simulations of tolerances show that the gun and magnetic system optics are robust, with misalignments of gun elements of \pm 0.1 $0.2 \mathrm{~mm}$ being acceptable.

The de-mountable gun engineering design is shown in Fig. 4. The sectioned insulator is $200 \mathrm{~mm}$ in length and $250 \mathrm{~mm}$ in diameter, and consists of ten sections. The shapes of intermediate electrodes and the cathode stem are optimized to provide uniformity along the insulator in the potential distribution to within 10\% (see Fig.5). A dispenser cathode with osmium coating manufactured by TORY (Moscow) is used. The cathode heater is potted. Temperature variation over the cathode surface $<5{ }^{\circ} \mathrm{C}$, and required heater power $<300 \mathrm{~W}$. The anode nose is made of molybdenum. The gun is installed with two 8 $1 / \mathrm{sec}$ pumps. All the critical elements are fabricated and assembled with accuracy $<0.1 \mathrm{~mm}$.

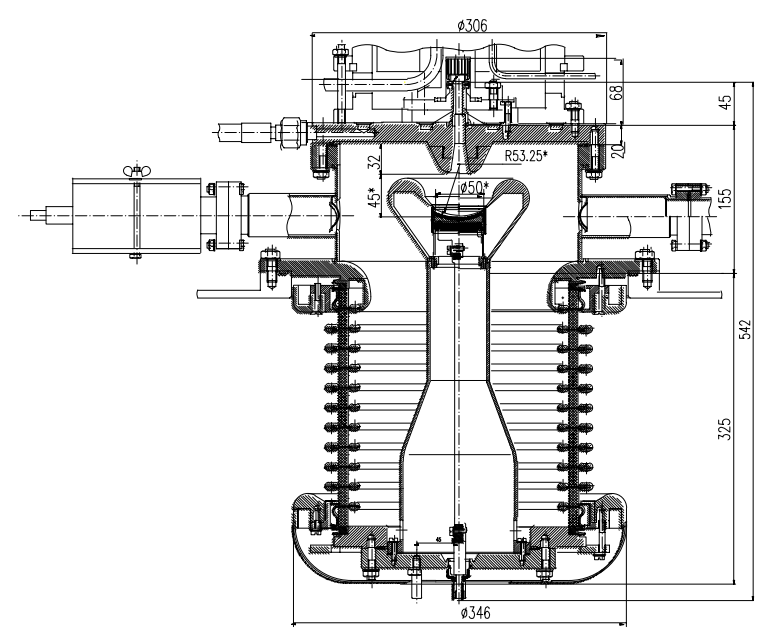

Figure 4. The gun engineering design.

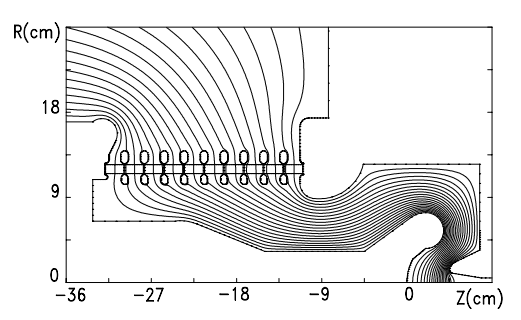

Figure 5 Equipotential lines calculated by SAM code [10].

\section{EXPERIMENT}

At present the gun is assembled with the magnicon collector [2] and has been tested up to the design power of $100 \mathrm{MW}$ in $\mu$ sec pulses at the Yale Beam Physics Lab.

The gun is driven by a $500 \mathrm{kV}$ pulse transformer and PFN modulator. Initial conditioning up to $\sim 515 \mathrm{kV}$ was carried out without beam current. To do this, a matched 
load was connected to the primary of the pulse transformer. The pulse is shown in Fig. 6.

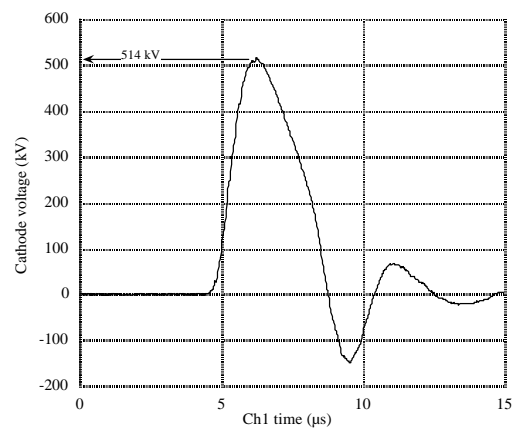

Figure 6. Conditioning pulse without beam current.

After cold conditioning, the gun was conditioned and tested hot up to $\sim 480 \mathrm{kV}$ and $\sim 200 \mathrm{~A}$. To reach $500 \mathrm{kV}$ small modifications in the modulator are required. The gun voltage and current pulses are shown in Fig. 7.

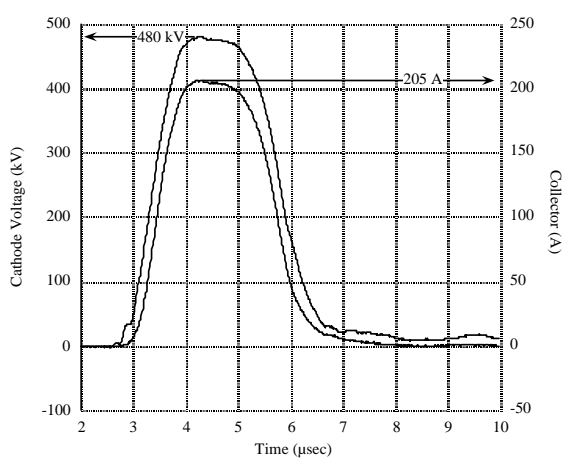

Figure 7. Measured gun voltage and current pulses.

The measured beam current is in excellent agreement with the design value, with differences within the measurement error, or better than $\pm 2 \%$. Gun current plotted $v s$ voltage is shown in Fig. 8. Measurements below $100 \mathrm{kV}$ were performed by vendor (Budker INP, Novosibirsk). Even for very small voltage $(2 \mathrm{kV})$ the

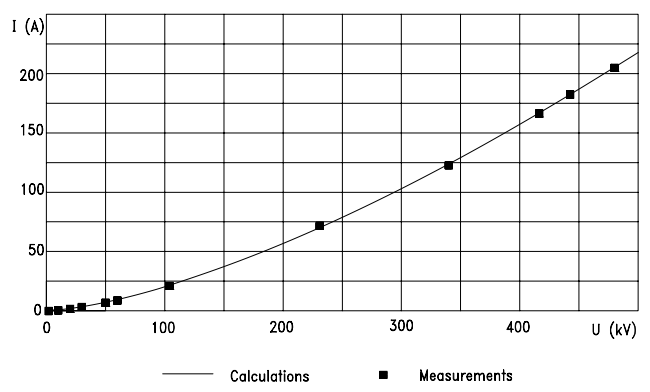

Figure 8. Beam current versus voltage. measured beam current is only $14 \%$ higher than the calculated value. This provides strong evidence that the cathode assembly is positioned with high accuracy with respect to the focus electrode, and that there is negligible electron emission from the cathode edges.

\section{CONCLUSIONS}

The gun has been tested and is ready for installation on the $34.3 \mathrm{GHz}$ magnicon. Beam current measurements show that the perveance is equal to the design value, within $\pm 2 \%$ measurement accuracy. This indicates that the critical gun dimensions are within required tolerances, and consequently that the electron optics should be close to the design.

The gun described here is the third 100 MW beam power level gun with high beam area compression (>1000:1) built for high-power magnicons. Experience with guns for the $7 \mathrm{GHz}$ magnicon [5] (having a measured beam area compression of 2300:1), and for the $11.4 \mathrm{GHz}$ magnicon [11] (having a compression of about 1500:1), shows that even if the gun is fabricated with unintended inaccuracy [11], and even if it's perveance differs from the design value as much as $10-15 \%$, that the measured beam diameter still exceeds the Brillouin limit by no more than $40 \%$. For the gun described here these considerations imply that the beam diameter will not exceed $1.0 \mathrm{~mm}$ in the magnicon's $13 \mathrm{kG}$ magnetic system, with an area compression ratio of greater than 2500:1.

\section{REFERENCES}

[1] O.A. Nezhevenko, Physics of Plasmas, vol.7 pp. 2224-2231, May 2000.

[2] O.A. Nezhevenko, et al, EPAC2000, pp.20872089. Viena, 2000.

[3] M. Catellino and G. Miram, Tri-Service Cathode Life Test Facility Annular Report, Dec. 1995.

[4] V.P. Yakovlev, O.A. Nezhevenko, AIP Proc. 474, Woodbury, N.Y., 1999, pp.316-326.

[5] Y.V. Baryshev, et al, Nucl. Instr. Methods Phys. Res., vol.A340, pp. 241-258,1994.

[6] V.P. Yakovlev, O.A. Nezhevenko and R.B. True, PAC97, Vancouver,1997, pp. 3186-3188.

[7] High Voltage Vacuum Insulation, Edited by R.V. Latham, Acad. Press, N.Y., 1995, pp.403-429.

[8] R. Koontz, et al, SLAC PUB 5257,1990.

[9] D.G.Myakishev, M.A.Tiunov and V.P.Yakovlev, Int. J. Mod. Phys. A (Proc. Suppl.) 2B (1993), v.2, pp. 915-917.

[10] M.A. Tiunov, B.M. Fomel, and V.P. Yakovlev, $13^{\text {th }}$ Int. Conf. High Energy Acc., Novosibirsk, 1987, v.1, p. 353.

[11] O.A. Nezhevenko et all, "Status of X-Band Pulsed Magnicon Project," present Conference. 